\title{
An Automated Measurement of Image Slice Thickness of Computed Tomography
}

\author{
S. Sofiyatun ${ }^{1 *}$, C. Anam ${ }^{1 *}$, U. M. Zahro ${ }^{1}$, D. A. Rukmana ${ }^{2}$, G. Dougherty ${ }^{3}$ \\ ${ }^{I}$ Department of Physics, Faculty of Sciences and Mathematics, Diponegoro University, Jl. Prof. Soedarto SH, \\ Tembalang, Semarang 50275, Indonesia \\ ${ }^{2}$ Radiology Department, Indriati Hospital Solo Baru, Jl. Palem Raya, Dusun III, Sukoharjo 57552, Indonesia \\ ${ }^{3}$ Department of Applied Physics and Medical Imaging, California State University Channel Islands, Camarillo, CA 93012, USA
}

\section{ARTICLE INFO}

Article history:

Received 27 December 2020

Received in revised form 17 April 2021

Accepted 17 April 2021

Keywords:

AAPM CT performance phantom

Automation

Computed tomography

Slice thickness

\begin{abstract}
A B S T R A C T
Measurement of the slice thickness in computed tomography (CT) is usually made using a special phantom, such as the AAPM CT performance phantom. Images of the phantom are analyzed manually and subjectively. The purpose of this study is to develop an automated system for measuring the slice thickness of the CT image of the phantom using MATLAB software. The CT AAPM performance phantom was scanned by a 128 multi-slice computed tomography scanner (Revolution Evo, GE Healthcare, Waukesha, WI) at a slice thickness of $5 \mathrm{~mm}$ with four different phantom orientations and also scanned by a 6 multi-slice CT scanner (Somatom Emotion 6 , Siemens AG, Forchheim, Germany) for two slice thicknesses of 5 and $10 \mathrm{~mm}$. Our automated method produced an accurate slice thickness value less than $0.5 \mathrm{~mm}$ different from the nominal slice thicknesses and manual measurements. Similar results were obtained when the phantom was rotated. This system is more objective and effective compared to manual systems.
\end{abstract}

(C) 2021 Atom Indonesia. All rights reserved

\section{INTRODUCTION}

Medical imaging is performed to detect disease due to physiological or pathological abnormalities [1]. Among the X-ray medical imaging modalities is computed tomography (CT) [2-4], which can detect very small differences of $\mathrm{X}$-ray absorption values represented in axial, coronal, and sagittal planes, or 3D [5]. The contrast of CT images is about 10 times higher than conventional X-ray radiography [6].

Due to its complexity, quality control of CT scanners must be periodically carried out $[7,8]$. A special phantom is usually used, such as the CatPhan phantom $[9,10]$, the ACR CT phantom [11], or the AAPM CT performance phantom $[12,13]$. The phantoms contain various inserts to quantify the parameters of scanners such as CT number linearity, spatial and contrast resolution, and slice thickness.

One of the important parameters that should be measured in quality control is the accuracy of the

\footnotetext{
*Corresponding author.

E-mail address: anam@fisika.fsm.undip.ac.id

DOI: https://doi.org/10.17146/aij.2021.1111
}

slice thickness between the machine setting and reality [10]. CT parameters such as the slice thickness have a direct impact on 3D images derived from volumetric data [14]. Large slice thickness causes the spatial resolution of the image to decrease in the $z$-axis direction [15]. This may lead to misidentification of small objects in the patient's body. Conversely, thin slice thickness results in more image noise and an increasing number of slices that make the image file size larger [16]. Hence, the selection of slice thickness needs to be optimized according to clinical applications.

The method of slice thickness testing depends on the types of phantoms used. In the ACR CT phantom, the slice thickness measurement is performed on the axial image by counting the number of discrete wires at the top and bottom $[9,12]$. In the CatPhan phantom, the full-width at half maximum (FWHM) of the profile for each wire ramp is measured then a trigonometric conversion is calculated based on the known ramp [10].

In the AAPM CT performance phantom, the slice thickness is measured from the image of the stair objects [12]. The thickness of the stairs describes the slice thickness [13] and can be 
measured using an electronic ruler on the console software. The measurement is usually performed manually by medical personnel and is subjective because the border at the end of the stair objects is relatively blurry.

To overcome this, the measurement of the slice thickness can be performed by analyzing the image profile of the stairs [13]. The result of the intensity values is depicted in a graph, and the slice thickness is determined as FWHM of the profile. Although it produces accurate results, this kind of manual measurement is tedious and timeconsuming.

This study aims to develop an algorithm in MATLAB software for the automated measurement of the slice thickness using the AAPM CT performance phantom and to evaluate slice thickness values on CT scanners for various different orientations of the phantom. The automatic measurement results will be compared with manual measurement.

\section{EXPERIMENTAL METHODS}

\section{Phantom materials and design}

Images of an AAPM CT performance phantom (Model 610, CIRS, Virginia, US) (Fig. 1a) was used. The object for determining slice thickness (part no. 610-04) was made from aluminum plates measuring $0.025^{\prime \prime} \times 1.00^{\prime \prime}$ with a water medium around it. It comprised three aluminum plates, each positioned at an angle of 45 degrees. The axial image of the object is shown in Fig. $1 b$.

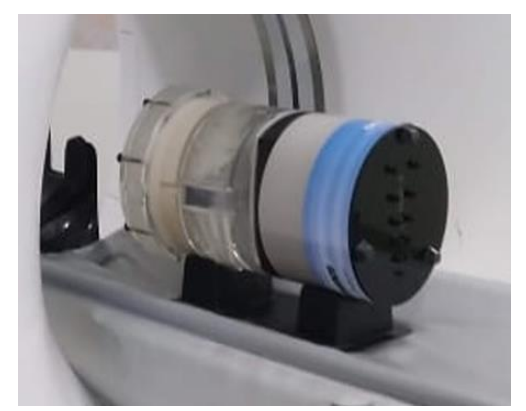

(a)

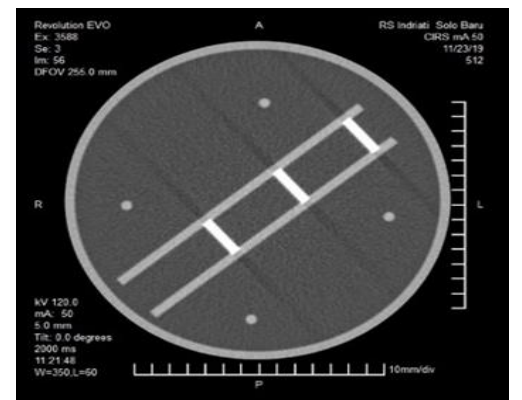

(b)

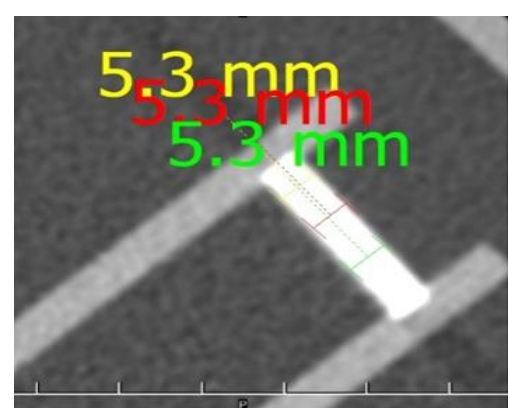

(c)

Fig 1. (a) AAPM CT performance phantom, (b) The axial image of part No. 610-04 of the phantom for slice thickness measurement, (c) The slice thickness value determined by using an electronic ruler on the console software (i.e. the manual measurement).

\section{The parameters of scanning}

Two CT scanners were used in this study. The first was a 128 multi-slice CT scanner (Revolution Evo, GE Healthcare, Waukesha, WI) (Fig. 2) and the second was a 6 multi-slice CT scanner (Somatom Emotion 6, Siemens AG, Forchheim, Germany).

The scanning parameters are shown in Table 1. MATLAB was used in coding and running the automated measurement of the slice thickness throughout the process. The algorithm was developed in-house, by detecting the phantom angle and then detecting the stair width of the phantom.

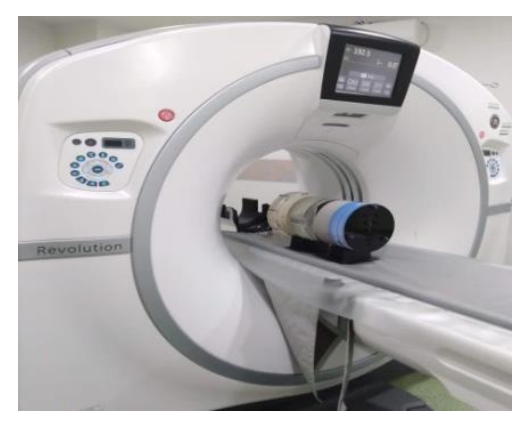

Fig 2. Placement of AAPM CT performance phantom during CT examination.

Table 1. Image acquisition parameters.

\begin{tabular}{ccc}
\hline \multirow{2}{*}{ Parameter } & \multicolumn{2}{c}{ Value } \\
\cline { 2 - 3 } & GE & Siemens \\
\hline Acquisition mode & Helical & Helical \\
Tube potential (kV) & 120 & 130 \\
Tube current (mA) & 50 & 54 \\
Pitch & 0.984 & 0.85 \\
Field of view (FoV) (cm) & 25.5 & 27 \\
Image reconstruction method & FBP & FBP \\
Rotation time (s) & 2 & 0.6 \\
Reconstructed slice thickness (mm) & 5 & 5 and 10 \\
\hline
\end{tabular}




\section{Automated measurement process}

The flowchart of the process for automated measurement of the slice thickness is depicted in Fig. 3 and the example results are shown in Fig 4. The algorithm was started with the segmentation of the stair objects in the image module. Image segmentation is a technique that divides the image into several regions based on the similarity of pixel values [17-19]. Since the stair object is an object with a pixel value of around $+350 \mathrm{HU}$ surrounded by water pixels of value around 0 HU [20], segmentation with athreshold value of $300 \mathrm{HU}$ was sufficient to obtain good results (Fig. 4b).

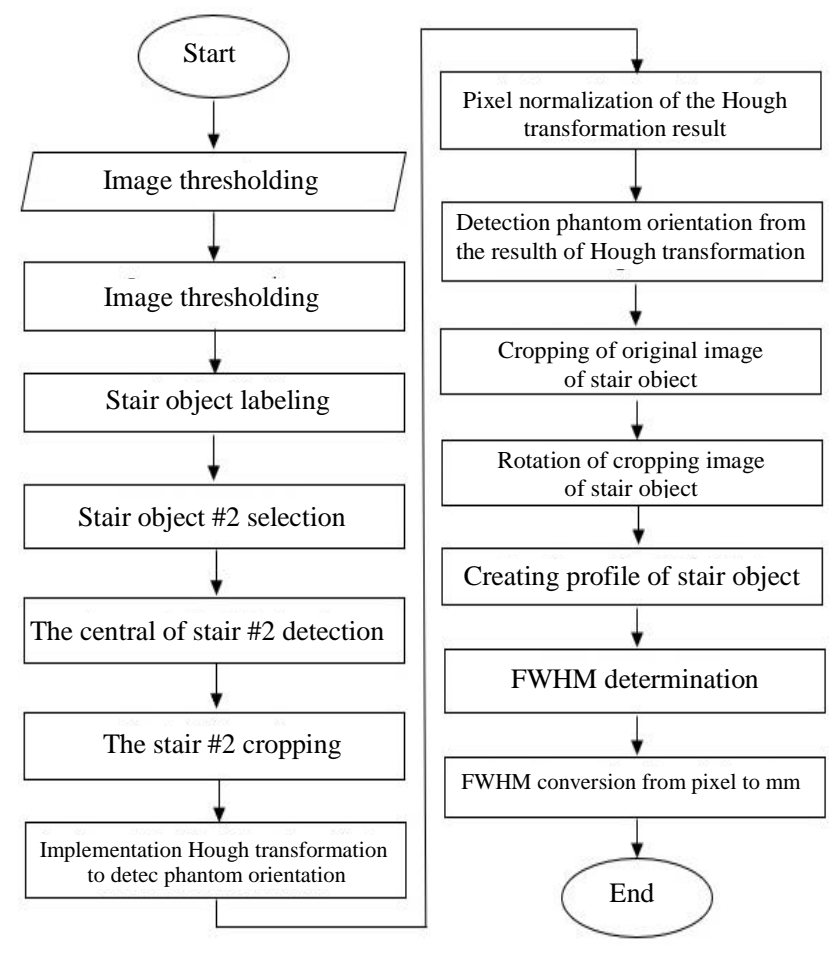

Fig 3. The flowchart of the automated measurement process.

The three stair objects were labeled after the segmentation process with number \#1 to \#3 (Fig. 4c), the middle one that is designated number \#2 was used to calculate the slice thickness and the other stairs were removed (Fig. 4d). The automated measurement can use all stairs or only one of them.

The position or $x-y$ coordinate of the center of the selected stair object was determined by its center point using the centroid method [21] in Eq. (1):

$$
\text { Centroid }=\frac{\sum y_{i}}{n_{y}}
$$

with $y_{i}$ as a pixel position in the stair objects and $n_{y}$ as the number of pixels in the selected stair object. The center position will be used to capture the original image with the same position (the center is indicated by the red dot in Fig. 4e). The next step was to crop the object to a size of $80 \times 80$ pixels (Fig. 4 f) in order to determine its angle using the Hough transformation [22].
It is noted that during the scanning process, medical personnel place the AAPM CT performance phantom without attention to its rotation aspect. Medical personnel usually only focus on whether the phantom is correctly at the iso-center and its position is not tilted. This is not a problem for manual calculation of slice thickness because medical personnel are able to find the orientation of the stair object visually, but it is a problem when calculating the slice thickness automatically. To solve this, the detection of rotation angle of the phantom was proposed using the Hough transformation.

The Hough transformation was performed by using Eq. (2):

$$
p=x_{i} \cos \theta+y_{i} \sin \theta
$$

where $p$ is the normal distance from the origin to the line, and $\theta$ is the angle between the normal and the $x$ axis. The Hough Transformation integrates the pixel value along a particular angle (0-180 degrees), then a projection at certain angles is obtained $[22,23]$. The result of the Hough Transformation is shown in Fig. $4 \mathrm{~g}$. Visually, we can determine that the angle of the phantom as the narrowest projection area.

The next step was to normalize all pixel values from the Hough Transformation [22]. All values greater than 1 were changed to 1 (Fig. $4 \mathrm{~h}$ ). The result of a 2D Hough transformation is composed of 1D transforms by summing all the pixels in the vertical direction that would form a 1D curve as in Fig. 4i. The angle of the phantom can then be easily and automatically determined (the smallest pixel value in (Fig. 4i).

The original image of the phantom was cropped to a size of $80 \times 80$ pixels in a central position based on centroid equation (Fig. 4j). The angle is obtained automatically from the Hough transformation (Fig. 4k), and then it re-cropped to 30 $\times 30$ pixels so that the rest of the background completely disappears from the image (Fig. 4l).

The profile across the stair was created by averaging the pixel values in the $x$-axis direction (Fig. $4 \mathrm{~m}$ ), and the height of the maximum profile value and the half profile value were determined [13]. Half of the maximum profile value is shown as the horizontal line in Fig. 4n. The full-width at half maximum (FWHM) of the curve was then calculated and converted to the length unit with a conversion factor in the form of pixel size taken from the DICOM header (Fig. 40).

MATLAB R2015b software was used in coding and running all these processes. The user only needs to tap a single button to execute them. A manual calculation of the slice thickness was also performed to validate the accuracy of this measurement. To ensure the accuracy of the algorithm at various angles, the automated method was also tested on four different placement angles of the phantom. 


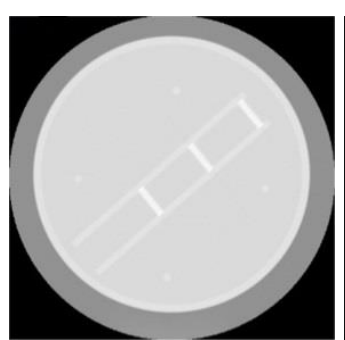

(a)

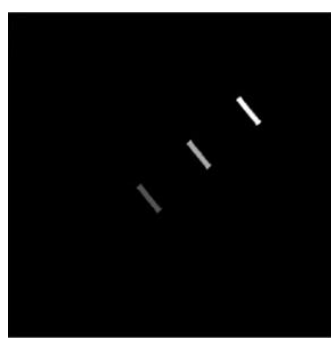

(c)

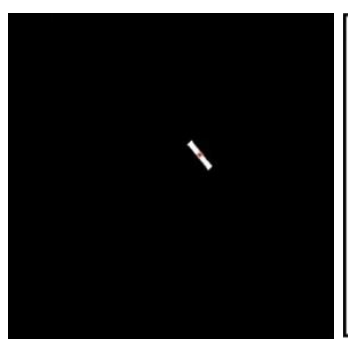

(e)

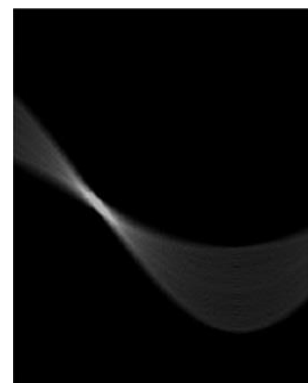

(g)

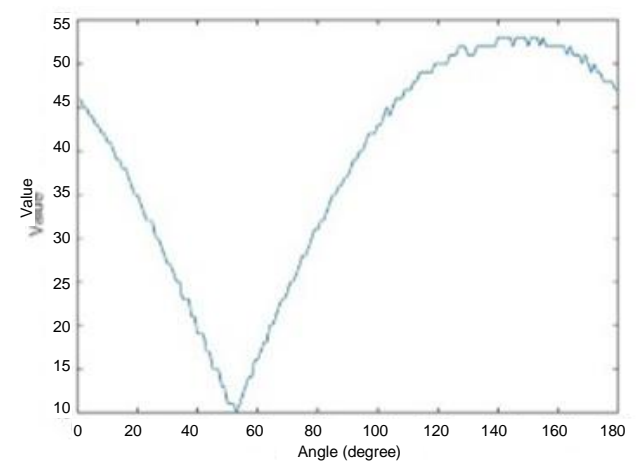

(i)

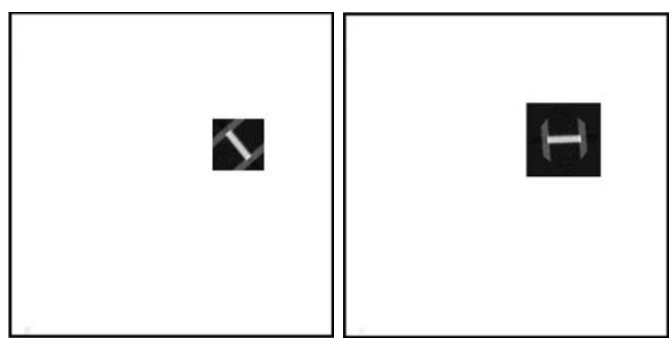

(j)

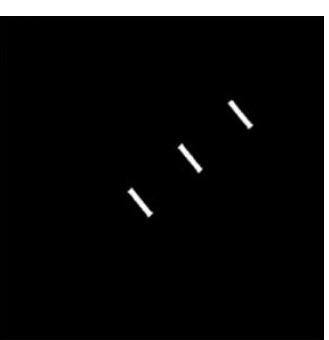

(b)

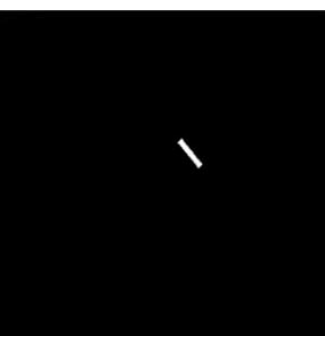

(d)

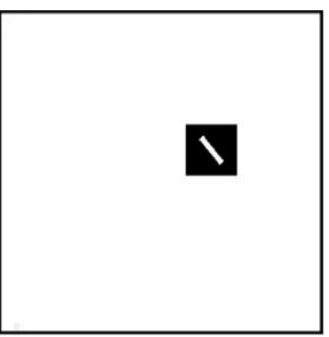

(f)

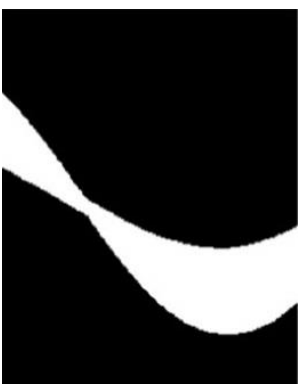

(h)

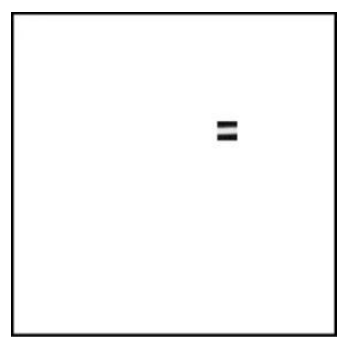

(1)

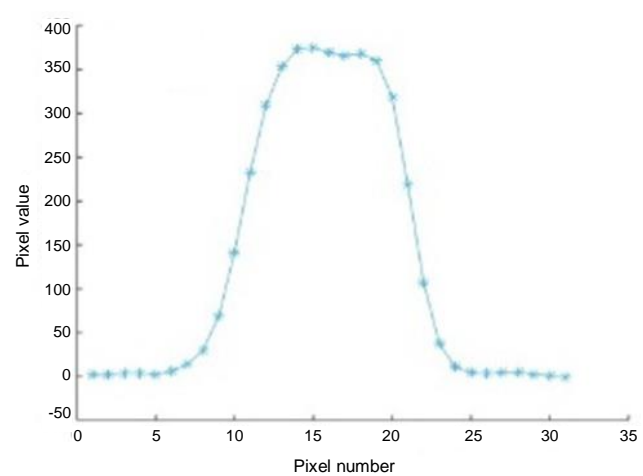

(m)

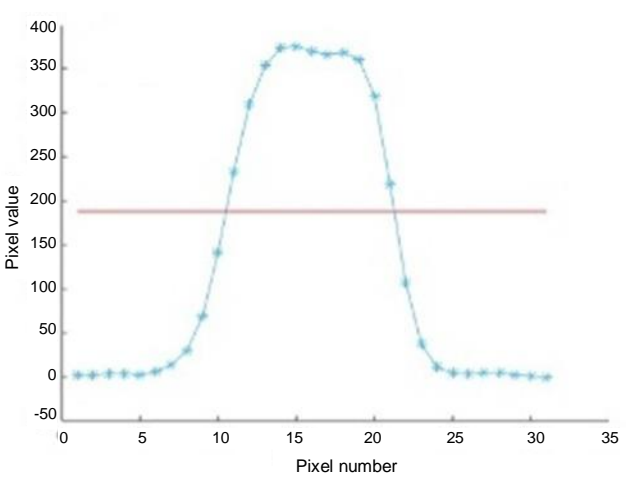

(n)

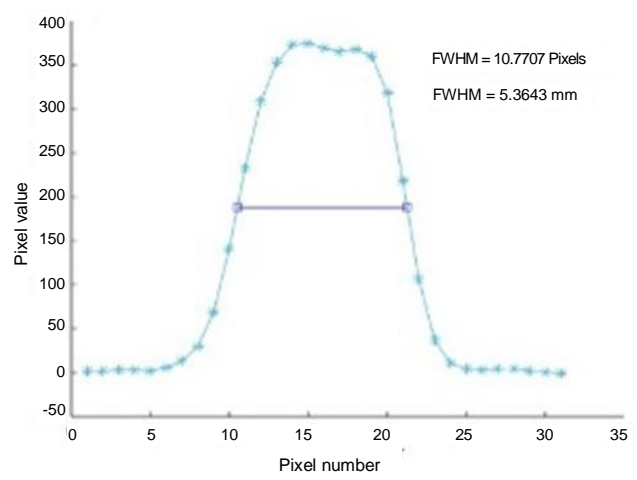

(o)

Fig 4. (a) Original image, (b) segmented image, (c) labeled image, (d) image for labeled object \#2, (e) image with the center position of labeled object \#2, (f) cropped image from labeled object \#2, (g) image result of Hough transformation, (h) image of the normalized result of Hough transformation, (i) integration of the result of Hough transformation to determine the minimum angle, (j) cropped image from original image, (k) rotated image, (l) recropped image, $(\mathrm{m})$ average profile, $(\mathrm{n})$ average profile with the half-peak line, and (o) average profile with FWHM value indicating the slice thickness. 


\section{RESULTS AND DISCUSSION}

Figure 5a shows images of the phantom with the angle variations. Figure $5 \mathrm{~b}$ shows the graphs of the Hough transformation results in 1D. Figure 5c shows the profile curves for the pixels across stairs and the FWHM which represents the slice thickness value. From Fig. 5b angle values can determined. The automated measurement values for 4 different angles are shown in Table 2, together with the slice thickness values obtained manually using the electronic ruler of CT software.

The automated measurement of the slice thickness has been successfully developed. This method could immediately acquire the slice thickness profile which is displayed with the FWHM value, both in pixels and mm units. To perform this automated measurement method, it requires to use an image in DICOM format.
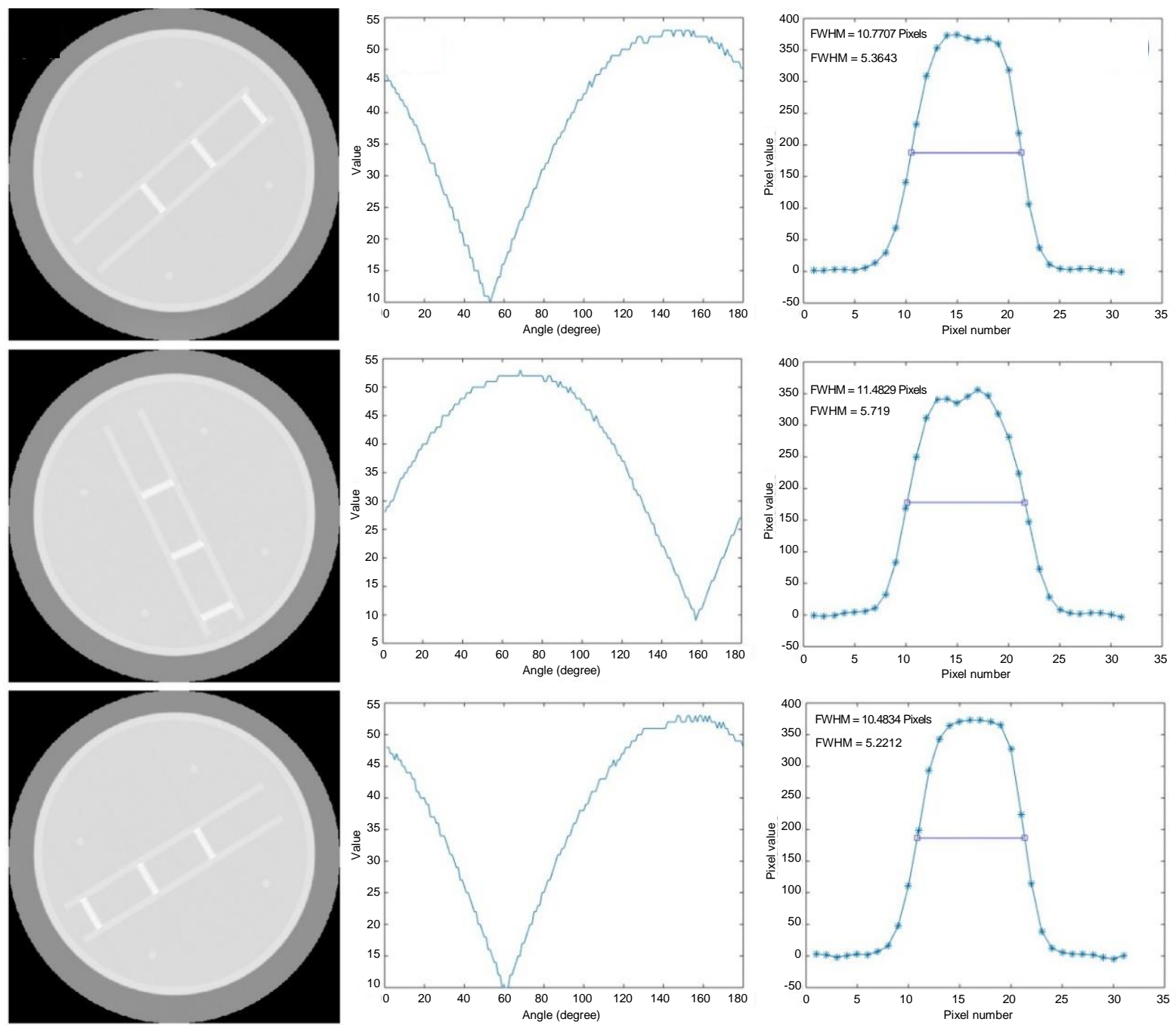

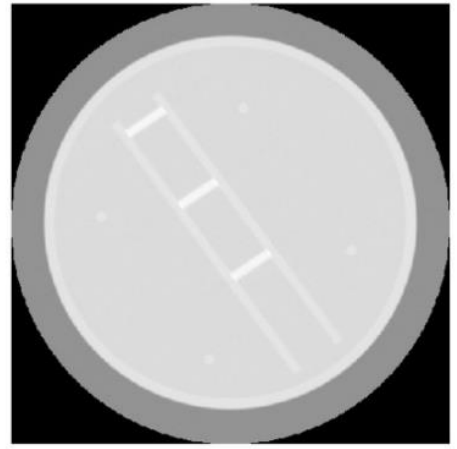

(a)

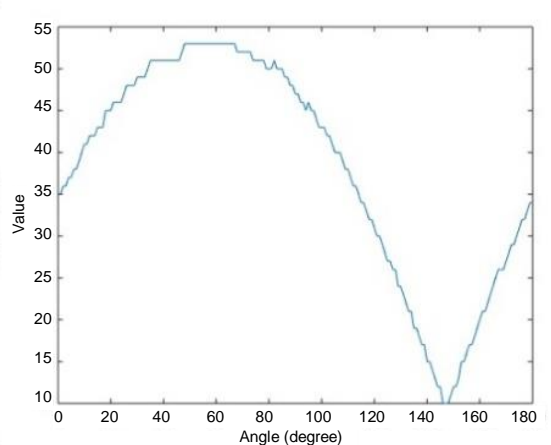

(b)

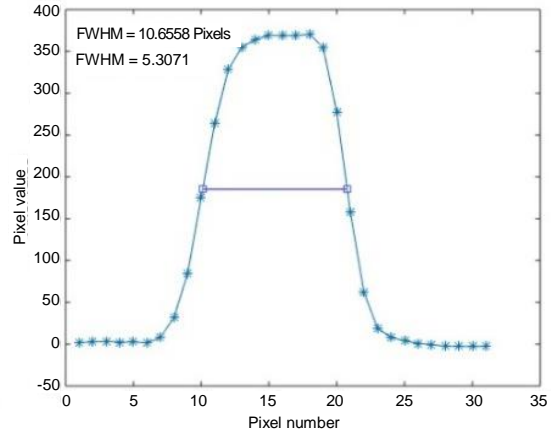

(c)

Fig 5. (a) Images of phantom scanned by a 128 multi-slice CT scanner (Revolution Evo, GE Healthcare, Waukesha, WI) at slice thickness of $5 \mathrm{~mm}$, (b) Results of Hough transformation, and (c) The profile curves and their FWHMs with the automated measurement method. First row is the first angle, second row is the second angle, third row is the third angle, and fourth row is the fourth angle. 
Table 2. The slice thickness results of the automated and the manual measurements at a nominal slice thickness of $5 \mathrm{~mm}$ with 4 angle variations for images of the phantom scanned by a 128 multi-slice CT scanner.

\begin{tabular}{cccccc}
\hline \multirow{2}{*}{$\begin{array}{c}\text { Angle } \\
\text { variation }\end{array} \begin{array}{c}\text { Nominal } \\
\text { slice } \\
\left.{ }^{\circ}\right)\end{array}$} & \multicolumn{3}{c}{ The slice thickness value (FWHM) } \\
\cline { 3 - 6 } & thickness & \multicolumn{2}{c}{ Automated } & \multicolumn{2}{c}{ Manual } \\
\cline { 3 - 6 } & $\begin{array}{c}\text { Value } \\
(\mathbf{m m})\end{array}$ & Mean \pm SD & $\begin{array}{c}\text { Value } \\
(\mathbf{m m})\end{array}$ & Mean \pm SD \\
\hline 53 & & 5.3 & & 5.7 & \\
159 & $5 \mathrm{~mm}$ & 5.4 & $5.4 \pm 0.1 \mathrm{~mm}$ & 5.6 & $5.7 \pm 0.1 \mathrm{~mm}$ \\
60 & & 5.3 & & 5.6 & \\
4 & & 5.5 & & 5.8 & \\
\hline
\end{tabular}

The slice thickness value obtained from this automated method $(5.4 \pm 0.1 \mathrm{~mm})$ is closer to the set value $(5 \mathrm{~mm})$ than the manual measurement $(5.7 \pm 0.1 \mathrm{~mm})$. The difference is less than $0.5 \mathrm{~mm}$ for all rotations of the phantom.

The automated system is capable of measuring the slice thickness at any angle so that it does not require any effort to place the phantom at a certain angle. The Hough transformation is applied to automatically detect the phantom angle based on the inclination of the stairs $[22,23]$. Thus, this system produces the slice thickness value objectively and independently of the operator.

Figure 6a shows images of the phantom with slice thicknesses of $5 \mathrm{~mm}$ and $10 \mathrm{~mm}$ for images of the phantom scanned by a 6 multi-slice $\mathrm{CT}$ scanner. Figure $6 \mathrm{~b}$ shows the graphs of the Hough Transformation results in one dimension. Figure $6 \mathrm{c}$ shows the profile curves for the pixels across the stairs and the FWHM which represents the slice thickness value. The automated and manual measurement values for the two slice thicknesses are shown in Table 3. Again, the differences between the results of automated measurements and nominal slice thicknesses are less than $0.5 \mathrm{~mm}$ in both cases.

Table 3. The slice thickness results of the automated and the manual measurements at nominal slice thicknesses of $5 \mathrm{~mm}$ and $10 \mathrm{~mm}$ for images of the phantom scanned by a 6 multi-slice CT scanner.

\begin{tabular}{cccc}
\hline \multirow{2}{*}{ Angle $\left(^{\circ}\right)$} & \multirow{2}{*}{$\begin{array}{c}\text { Nominal slice } \\
\text { thickness }\end{array}$} & \multicolumn{2}{c}{ The slice thickness value (FWHM) } \\
\cline { 3 - 4 } & & Automated & Manual \\
\hline 78 & $5 \mathrm{~mm}$ & $5.0 \pm 0.1 \mathrm{~mm}$ & $5.3 \pm 0.2 \mathrm{~mm}$ \\
91 & $10 \mathrm{~mm}$ & $9.5 \pm 0.1 \mathrm{~mm}$ & $9.7 \pm 0.4 \mathrm{~mm}$ \\
\hline
\end{tabular}
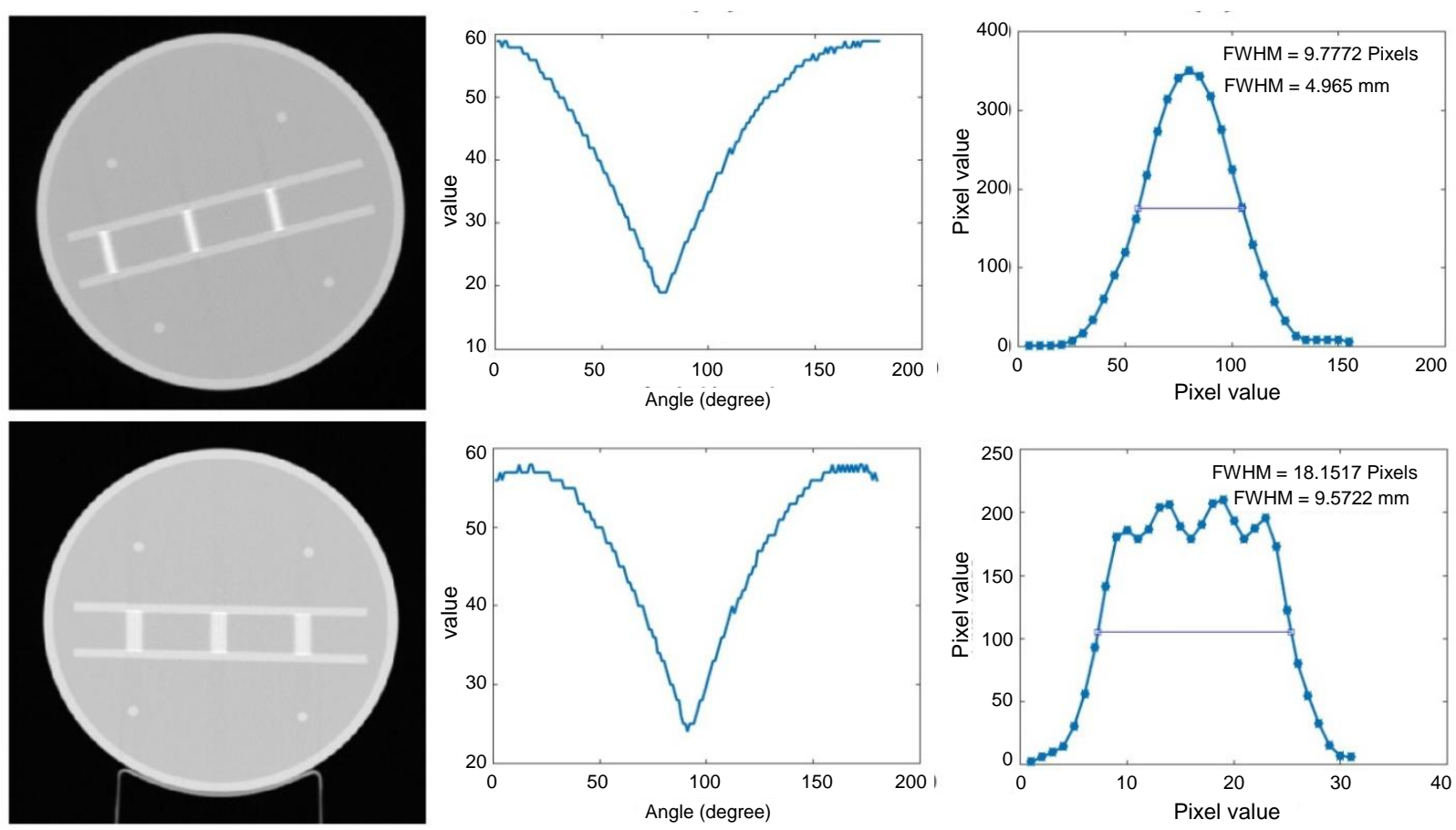

(a)

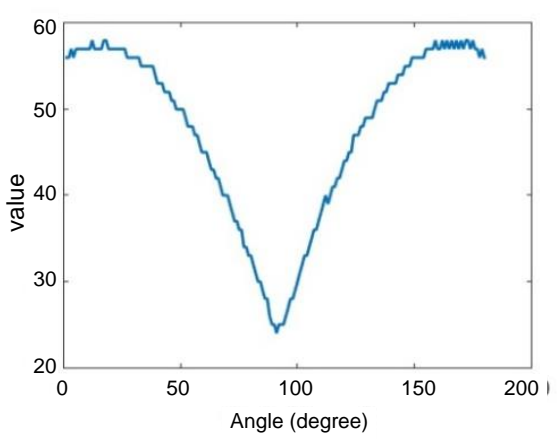

(b)

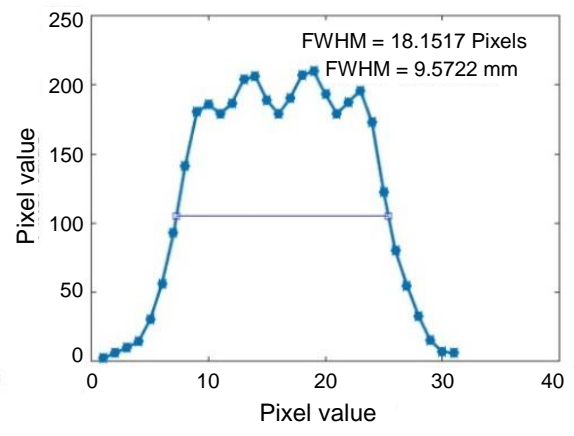

(c)

Fig 6. (a) Images of phantom scanned by a 6 Multi-Slice CT Scanner (Revolution Evo, GE Healthcare, Waukesha, WI), (b) Results of Hough transformation, and (c) The FWHM curves with the automated measurement method. First row is for slice thickness of $5 \mathrm{~mm}$ and second row is for slice thickness of $10 \mathrm{~mm}$. 
As mentioned, the slice thickness measurement on CT can be performed using several types of phantom [9-13]. The AAPM CT performance phantom has one advantage over other the phantoms. The slice thickness can be obtained objectively by using profile across the stair values, and the FWHM value is determined to indicate the slice thickness value of the image. Makmur et al. [13] performed an objective measurement using the AAPM CT performance phantom and obtained accurate results, but their method is impractical and time-consuming. The development of automated measurement of the slice thickness using software like MATLAB offers a significant benefit. In this study, we showed that automated measurement is more accurate, practical, easy to use, and less timeconsuming. The user only needs to tap a single button to execute them.

It should be noted that our automated method of measuring the slice thickness is only applicable to the AAPM CT performance phantom [13]. The image thickness of each stair object represents the value of the slice thickness, hence only one of the three stairs needs to be selected. We only used the middle stair in the current study. Use of all the stair objects for slice thickness measurements will be conducted in the next study.

We only used a nominal beamwidth of 5 and $10 \mathrm{~mm}$ at one field of view (FOV). Evaluation for other slice thicknesses and for various FOV values needs to be performed in future studies.

In the current study, it was assumed that the maximum value is the reference, and based on it, the middle value to determine FWHM was determined. This does not guarantee that the maximum value is at the middle of the profile. To overcome this, implementation of Gaussian fitting might yield better results and will be used in future studies.

The AAPM CT performance phantom contains various inserts to quantify the parameters of scanners, such as CT number accuracy, CT numbers linearity, spatial resolution, low contrast detectability, and slice thickness. Automation of these other parameters will be presented in a further study.

\section{CONCLUSION}

An algorithm for automated measurement of slice thickness using AAPM CT performance has been successfully developed using MATLAB software. The method was easily implemented and requires only a single tap on a button. The difference in the results between the automated method and the manual method is less than $0.5 \mathrm{~mm}$. The phantom, which was rotated with four angle variations, could accurately be detected using the operation of Hough transformation. Since this algorithm was tested only on two slice thicknesses, the current study is considered as an initial proof of concept. It is necessary to test this algorithm on various slice thicknesses from less than $0.1 \mathrm{~mm}$ to more than $20 \mathrm{~mm}$, the range of slice thicknesses that is commonly used in clinical practice.

\section{ACKNOWLEDGMENT}

This work was funded by the Riset Publikasi International Bereputasi Tinggi (RPIBT), Diponegoro University (Contract Numbers: 329-116/UN7.6.1/ PP/2021).

\section{AUTHOR CONTRIBUTION}

S. Sofiyatun and C. Anam conceived of the idea. S. Sofiyatun developed the theory and performed the computations with C. Anam. U. M. Zahro and D. A. Rukmana provided the research data. C. Anam and G. Dougherty assisted S. Sofiyatun in writing the paper. All authors approved the final version of the paper.

\section{REFERENCES}

1. D. R. Dance, S. Christofides, A. D. A. Maidment et al., Diagnostic Radiology Physics: A Handbook for Teachers and Students, International Atomic Energy Agency (IAEA), Vienna (2014).

2. K. Sato, M. Abe and T. Takatsuji, Precis. Eng. 54 (2018) 276.

3. T. A. Bjarnason, R. Rees, J. Kainz et al., J. Appl. Clin. Med. Phys. 21 (2020) 10.

4. C. Anam, F. Haryanto, R. Widita et al., J. Appl. Clin. Med. Phys. 17 (2016) 320.

5. H. Y. Wang, Y. X. Jiang, Q. L. Zhu et al., Ultrasound Med. Biol. 42 (2016) 689.

6. A. Ferrero, N. Takahashi, T. J. Vrtiska et al., Nat. Rev. Urol. 16 (2019) 231.

7. Z. Mansour, A. Mokhtar, A. Sarhan et al., Egypt. J. Radiol. Nucl. Med. 47 (2016) 1665.

8. G. R. Iball, A. C. Moore and E. J. Crawford, J. Appl. Clin. Med. Phys. 17 (2016) 291.

9. E. Husby, E. D. Svendsen, H. K. Andersen et al., J. Appl. Clin. Med. Phys. 18 (2017) 224. 
10. F. van Ommen, E. Bennink, A. Vlassenbroek, et al., Med. Phys. 45 (2018) 3031.

11. J. M. Hoffman, F. Noo, S. Young et al., Med. Phys. 45 (2018) 3591.

12. D. Sharma, S. Sharma, K. Sanu et al., J. Med. Phys. 31 (2006) 28.

13. I. W. A. Makmur, W. Setiabudi and C. Anam, J. Sains \& Mat. 21 (2013) 42. (in Indonesian)

14. Q. Li, Y. Liang, Q. Huang et al., Med. Phys. 43 (2016) 6608.

15. D. Goodenough, J. Levy, S. Kristinsson et al., Med. Phys. 17 (2016) 440.

16. F. Morsbach, Y. H. Zhang, L. Martin et al., Nutr. 59 (2019) 50.
17. F. Spagnolo, S. Perri and P. Corsonello, Sens. 19 (2019) 3055.

18. P. F. Raudaschl, P. Zaffino, G. C. Sharp et al., Med. Phys. 44 (2017) 2020.

19. R. B. Holmes, I. S. Negus, S. J. Wiltshire et al., Med. Phys. 47 (2020) 2380.

20. J. Qiu, H. H. Li, T. Zhang et al., J. Appl. Clin. Med. Phys. 18 (2017) 218.

21. N. Afrieda, C. Anam, W. S. Budi et al., J. Phys: Conf. Ser. 1505 (2020) 012034.

22. R. Smith, K. Najarian and K. Ward, BMC Med. Inform. Decis. Mak. 9 (2009) 1.

23. R. Fang, J. Yang, W. Du and L. Court, J. Appl. Clin. Med. Phys. 20 (2019) 18. 